\title{
Os estudos biográficos como contributo metodológico para o campo educativo-ambiental: reflexões a partir de uma experiência investigativa com famílias assentadas no Rio Grande do Sul, Brasil
}

\author{
Marcelo Gules Borges ${ }^{1}$ \\ Marília Andrade Torales ${ }^{2}$ \\ Teresinha Guerra ${ }^{3}$
}

Resumo: Este artigo busca evidenciar a contribuição dos estudos biográficos para o campo da Educação Ambiental através do relato de uma pesquisa realizada com famílias assentadas no bioma Pampa, Rio Grande do Sul, Brasil. A argumentação se sustenta na descrição do percurso metodológico que possibilitou a compreensão dos significados atribuidos à paisagem (de origem e de destino) por três gerações de famílias, identificando os elementos que constituíram e influenciam as relações entre seus pares e os lugares. Apresenta-se e discute-se uma abordagem qualitativo-biográfica - história de vida familiar - dando-se ênfase às especificidades das técnicas utilizadas como um caminho para estabelecer o diálogo entre os sujeitos biografados e suas trajetórias, bem como à potencialidade dessa abordagem como método de pesquisa com famílias. A exploração desse viés metodológico possibilitou múltiplas perspectivas para compreender as relações dos membros familiares entre si e com os lugares em que transcorrem as histórias de vida reconstituídas. Destacamos a particularidade dos estudos qualitativo-biográficos por permitirem outros níveis de interpretação fundamentais ao desenvolvimento de estratégias de intervenção no campo educativo-ambiental, no qual as pessoas e as famílias são o foco de investigação.

Palavras-chave: Metodologia. História de vida familiar. Educação Ambiental.

Biographical studies as a methodological contribution to the field of environmental education: reflections from an investigative experience with families settled in Rio Grande do Sul, Brazil

Abstract: This paper seeks to point out the contribution of biographical studies to the field of environmental education by reporting a research with families settled in the Pampa biome, Rio Grande do Sul, Brazil. The argumentation is based on the description of the methodological path that made it possible to understand the meanings assigned to the landscape (of origin and destination) by three generations of families, identifying the elements that constitute and influence their relationships with their peers and places. The paper also presents and discusses a qualitative and biographical approach - family life history - emphasizing both the

1 Doutorando em Educação na PUC-RS. marcelogulesborges@gmail.com

2 Professora adjunta da UFPR. marilia.torales@ufpr.br

3 Professora do Dep. de Ecologia e do PPG em Ecologia do IB da UFRGS. tg@ufrgs.br 
specific techniques used as a way to allow for the dialogue between individuals and their paths, and the potential of this approach as a research method for families. This methodological orientation allowed multiple perspectives to understand social relations within the family and with the places related to their life histories. We highlight the peculiarity that biographical studies allow other levels of interpretation that are fundamental to the development of intervention strategies in the environmental education field, in which people and families are the focus of investigation.

Keywords: Methodology. Family life history. Environmental Education.

\section{Introdução}

As temáticas de pesquisa em Educação Ambiental são diversas e complexas, exigindo do pesquisador o desenvolvimento de habilidades e sensibilidades na construção de rigorosos procedimentos metodológicos. Nessa tessitura, propomos uma reflexão fundamentada na experiência obtida ao longo do desenvolvimento de uma pesquisa com famílias que vivem em assentamentos rurais no interior do Rio Grande do Sul, em especial tomando como objeto de análise as opções metodológicas que permitiram o desvelamento de dados complexos e permeados de aspectos subjetivos dos sujeitos em seus grupos familiares.

Pela complexidade da temática, foi preciso compor um mosaico de referentes teóricos para sustentar as necessidades reflexivas da pesquisa. Nesse sentido, valeria destacar que na base do debate teórico usamos referências tanto das Ciências Sociais (BERTAUX, 1994; BERTAUX; BERTAUX-WIAME, 2006; BERTAUX; DELCROIX, 2000; CUÉLLAR, 2004; GONZÁLEZ, 1995; PLUMMER, 2007) quanto da Educação Ambiental (CARVALHO, 2002; LISBOA, 2007; TORALES, 2006, 2008).

Por outro lado, considerando que o referencial metodológico sustenta e dá rigorosidade ao processo de pesquisa, nos propusemos a refletir e problematizar os aspectos que emergem do processo investigativo. Mais especificamente, por se tratar de um estudo qualitativo de corte biográfico, tomamos como objetivo a tarefa de descrever e analisar as implicações do uso dessa metodologia para o campo ambiental tendo como base a (re)construção da História de Vida de três gerações de três famílias migrantes.

O desenvolvimento de uma pesquisa pressupõe uma relação entre método e conteúdo, numa constante rigorosidade ${ }^{4}$ entre o formal e a fundamentação teórica que sustenta o estudo. Esse rigor não significa assumir uma tendência positivista, entendida como fragmentária e com ênfase em processos de absolutização da verdade ou em conformidade com "as imposições da epistemologia do positivismo” (BOURDIEU, 1987, p. 49); ao contrário, se considera que o rigor permite dar credibilidade a diversos aspectos de um

\footnotetext{
4 Rigor científico: refere-se à "credibilidade (validez interna), transferência (validez externa), consistência (aplicabilidade) e confirmabilidade (fiabilidade externa)" (PÉREZ SERRANO, 1994, p. 89, tradução nossa).
} 
fenômeno que somente poderiam ser visíveis através do cumprimento de determinadas normas do campo científico.

Outra contribuição dos estudos biográficos é dar voz aos protagonistas do processo a ser investigado (BUTT et al., 2004; GOODSON, 2004) em vez de falar por eles através de estudos teóricos. Por meio de sua linguagem, os participantes são capazes de descrever suas iniciativas, aspirações, frustrações e entendimentos relacionados a suas próprias experiências.

Vale esclarecer que o relato de vida é uma narração realizada a partir da própria trajetória vital do sujeito, enquanto a história de vida é um relato situado em determinado contexto histórico, com a intervenção de terceiros, pois a história não fala por si mesma, deve ser organizada, contextualizada e conceitualizada. Portanto, esse processo exige compromisso ético do pesquisador e domínio das técnicas de narração de histórias. A elaboração das histórias de vida se fundamenta no entendimento das relações que os sujeitos estabelecem consigo, com os outros e com o mundo, a fim de compreender a pessoa, as outras pessoas e o entorno, considerando que o percurso vital de cada indivíduo poderia constituir-se em uma via de conhecimento do universo social.

O uso das histórias de vida tem por base uma concepção que leva em conta a história pessoal e social dos sujeitos em um determinado contexto a fim de "analisar a relação entre suas biografias individuais, os acontecimentos históricos e as limitações que as relações de poder, como de classe, raça e gênero, impõem sobre suas opções pessoais" (MIDDLETON, 2004, p. 64). Nessa aproximação desvelam-se as conexões que se estabelecem a partir da interpretação que o sujeito faz do mundo e de si mesmo, na (re)ação com outros, pois estes condicionam a sua possibilidade de estar no mundo e atribuir sentido a essa dinâmica.

É importante ressaltar ainda que este estudo surgiu a partir do projeto de intervenção denominado Programa Integrado de Recuperação e Conservação dos Recursos Naturais em Assentamentos Rurais localizados no Municipio de Santana do Livramento, RS, Brasī̄ realizado através de convênio entre o Instituto Nacional de Colonização e Reforma Agrária (INCRA) e o Núcleo de Estudos em Educação Ambiental (NEEA) do Centro de Ecologia da Universidade Federal do Rio Grande do Sul (UFRGS).

\section{O método escolhido: abordagem qualitativa de corte biográfico}

O percurso metodólogico em uma pesquisa é a etapa primordial. Além de demarcar o campo científico no qual o trabalho se insere, revela e qualifica o referencial teórico envolvido na investigação. Assim, a metodologia pode ser compreendida de forma mais ampla, considerando que não se trata apenas de

\footnotetext{
${ }^{5}$ Este projeto vem sendo realizado desde 2007 em 13 assentamentos rurais localizados no bioma Pampa, Rio Grande do Sul, Brasil. Tem por objetivo a construção, a partir de metodologias participativas, de uma unidade de referência voltada para a sustentabilidade socioambiental das comunidades locais.
} 
uma descrição sumária de aspectos formais, "inclui concepções teóricas da abordagem, articulando-se com a teoria, com a realidade empírica e com os pensamentos sobre a realidade" (MINAYO, 1993, p. 15). Para Demo (1981, p. 8), a metodologia é, antes de qualquer outra coisa, o "estudo dos instrumentos de montagem de uma teoria, o estudo dos arcabouços teóricos, não entrando apenas a preocupação teórica, mas também a preocupação empírica".

A decisão do método se dá a partir de alguns elementos a priori na constituição de uma investigação. Em primeiro lugar, é preciso ter clareza a respeito da pergunta de partida, ou seja, do que se quer investigar. Em segundo lugar, é preciso reconhecer que essa indagação tem uma relação direta com a história do investigador, com sua trajetória formativa. Como consequência, quem define o método é o objeto e quem define o objeto é o investigador (comunidade científica na qual se insere).

O melhor método e/ou técnica é aquele que melhor responde às exigências do objeto de estudo, ou seja, "é o próprio objeto de pesquisa em relação a outros elementos que compõem o quadro investigativo que define, em função de suas características, o uso do método apropriado" (TORALES, 2008, p. 79). Independentemente da abordagem (quantitativa e/ou qualitativa), o método deve obedecer a esse critério.

Nesta pesquisa, o método qualitativo significou a melhor opção metodológica considerando as características do objeto de estudo e do campo educativo-ambiental. Destacamos que nosso interesse foi compreender os significados da paisagem como forma de interpretar a relação das famílias migrantes nos/com os lugares (de origem e de destino) com base em uma perspectiva geracional. A pesquisa qualitativa ${ }^{6}$ se revela como a possibilidade de compreensão em profundidade dos significados e, a partir desses, a busca pela interpretação dos fenômenos sociais que envolvem os grupos humanos.

Vale lembrar que os estudos de Callejas (2008), desenvolvidos em uma comunidade indigena em território andino-boliviano e no campo da Educação Ambiental, destacam que os acontecimentos $\mathrm{e}$ as ações humanas têm um significado que supera o nível do meramente quantificável, já que se guiam por valores e propósitos, além de estarem orientados a uma ou várias finalidades. Por outro lado, escondem uma estrutura profunda de sentimentos, paixões, esperanças e projetos a qual dificilmente pode ser objeto de uma expressão paramétrica.

Neste estudo, além de conceber o método como uma etapa formativa importante ao pesquisador, a abordagem qualitativa se justificou pelos pressupostos apresentados. Assim, a ênfase deu-se em revelar contextos da vida familiar que pudessem contribuir para a intrepretação dos significados, os quais são construídos na intersecção da subjetividade individual e do grupo social.

\footnotetext{
${ }^{6}$ De acordo com Gómez, Flores e Jiménez (1996, p. 24), a pesquisa qualitativa nasceu dos estudos etnográficos (antropologia e sociologia) a partir dos séculos XV e XVI, em especial daqueles relacionados aos interesses dos ocidentais nas origens da cultura e da civilização dos povos "primitivos".
} 
Os critérios de validade e de definição da amostra obedeceram aos pressupostos da pesquisa qualitativa, bem como, relativos a restrição do tempo e financeira. Por sua abordagem biográfica, este estudo se constituiu em uma amostragem intencional e casuística na qual os informantes foram selecionados de acordo com certo número de critérios estabelecidos pelo investigador (BURGESS, 1997). Esses priorizaram, mais do que conhecer as trajetórias individuais, localizá-las em um coletivo (grupo familiar) a fim de descrever e interpretar em profundidade como a família significa a paisagem e a sua relação com o lugar de origem e de destino.

Para a reconstrução da História de Vida familiar foram selecionados sujeitos de três gerações de três famílias (avós, pais e filhos), havendo no mínimo um informante por geração, considerando que as famílias fossem da mesma localidade de origem ${ }^{7}$, que as gerações pudessem descrever as vivências no lugar de origem e de destino e que todos os membros da família tivessem passado pelo processo de migração.

\section{As técnicas utilizadas: entrevistas individuais e coletivas}

A entrevista é uma das principais técnicas utilizadas em pesquisa qualitativa. Dependendo do referencial teórico, apresenta diversas definições e tipologias. Não há, portanto, "uma teoria dos inquéritos, mas sim um conjunto de questões teóricas, epistemológicas e metodológicas muito diversas" (GHIGLIONE; MATALON, 2005, p. 1). A complementaridade propiciada pela interação das diferentes técnicas permite uma ampla identificação dos acontecimentos e contextos nas trajetórias individuais e geracionais vivenciadas no grupo familiar.

Partilhamos a perspectiva de Gaskell (2004, p. 73), segundo a qual a entrevista é "um processo social, uma interação ou um empreendimento cooperativo em que as palavras são o meio principal de troca" entre entrevistado e entrevistador. Ou seja, é a partir dela que o pesquisador é capaz de criar esquemas interpretativos para compreender as narrativas dos atores em termos mais conceituais e abstratos, muitas vezes em relação a outras observações.

Mais especificamente, os estudos de abordagem biográfica, nos quais o enfoque é a reconstrução de ações passadas, têm como principal técnica a entrevista em profundidade (BOGDAN; TAYLOR, 1975; CHASE, 2000; GASKELL, 2004). Sua singularidade reside no fato de permitir aprofundar informações contidas na biografia do informante, entendidas como "o conjunto de representações associadas aos acontecimentos vividos pelo(s) entrevistado(s)" (ALONSO, 1995, p. 226, tradução nossa).

\footnotetext{
${ }^{7}$ Nesta pesquisa o lugar de origem das famílias são três comunidades rurais inseridas no território indígena caingangue das Reservas Indígenas de Nonoai e Serrinha (bioma Mata Atlântica), localizadas no norte do estado do Rio Grande do Sul. O lugar de destino são dois assentamentos rurais localizados em Santa do Livramento (bioma Pampa), no sul do estado do Rio Grande do Sul, na fronteira com o Uruguai.
} 
No caso desta pesquisa, foram realizadas 13 entrevistas em profundidade (individuais), com no mínimo uma entrevista por geração, entre os períodos de março de 2008 e janeiro de 2009. Todas as entrevistas foram gravadas com o consentimento dos informantes e duraram aproximadamente de 60 a $80 \mathrm{mim}$. Com o intuito de realizar as entrevistas de forma a descrever a trajetória individual no grupo familiar, atendendo aos objetivos do estudo, foi utilizado um guia de entrevista (lugar de origem, migração e lugar de destino) e outro de temas (comunidade, ambiente e paisagem).

Não se estabeleceu nenhum critério em relação à ordem das gerações para a realização das entrevistas individuais, mas se optou por concluí-las primeiro com todas as gerações antes de realizar as entrevistas coletivas (grupo familiar). Essa opção minimizou futuros enviesamentos nas respostas provocados pela influência dos outros membros da família, ou seja, a natureza do processo coletivo poderia direcionar as narrativas individuais. Assim, era melhor iniciar pela ótica individual, para que cada um pudesse particularmente descrever seu relato, e depois encontrar elementos e tramas comuns.

Estabeleceu-se, tanto nas entrevistas individuais como nas coletivas, o critério de saturação para o término da coleta de dados, sendo essa saturação atingida quando o pesquisador presume não obter mais informações que qualificam os dados existentes, ou seja, quando nada de novo está sendo adicionado aos dados (BOWEN, 2008; GASKELL, 2004). Essa percepção, de caráter subjetivo, para além dos conhecimentos téoricos e técnicos que envolvem a dimensão metodólogica, refere-se ao envolvimento do pesquisador no trabalho de campo, no domínio e nos dados obtidos, bem como na etapa de análise dos resultados.

Por outro lado, as entrevistas coletivas (grupo focal) se constituem em conversações coletivas sobre um determinado tema, permitindo ao pesquisador compreender um tópico particular na perspectiva dos participantes do grupo. Caracteriza-se como um momento de participação de mais de um informante por meio do qual se tenta contrastar as informações que constituem os dados, sendo um debate "aberto e acessível a todos: os assuntos em questão são de interesse comum; as diferenças de status entre os participantes não são levadas em consideração" (GASKELL, 2004, p. 79), o que permite constrastar também as subjetividades dos indivíduos, as quais estão condicionadas ao contexto social e histórico.

Ao longo de nosso percurso investigativo, as entrevistas coletivas assumiram um papel fundamental na complementação das narrativas individuais, considerando que estas "são sempre representações de caráter coletivo, não individual” (ALONSO, 1995, p. 227). Elas permitiram aos sujeitos complementar, aprofundar e debater momentos específicos vivenciados em família, o que enriqueceu as narrativas no tocante à formação da história de vida familiar e à possibilidade de interpretação profunda dos significados da paisagem para os sujeitos e da sua relação com os lugares (de origem e de destino).

Esses encontros revelaram-se momentos de aprendizagem coletiva e de trocas e renegociações dos significados individuais em direção a uma visão coletiva, (re)criadora das identidades individuais e do grupo familiar. Além disso, 
enquanto espaço de intervenção educativa, se tornou um momento de intensa afetividade, muitas vezes contribuindo para a resolução de conflitos familiares.

\section{Das narrativas individuais e coletivas à (re)construção das histórias de vida familiar}

Após a definição do método, da amostra e das técnicas e a coleta e transcrição dos dados, chega o momento de organizar e analisar todo o material empírico. Para isso foi preciso tratar os dados a fim de transformar as narrativas individuais e coletivas em um corpus (GASKELL, 2004; MORAES, 2007) que representasse, no caso desta pesquisa, a história de vida familiar temporalizada e tematizada a partir do processo de migração do lugar de origem ao de destino, juntamente com a construção de um genograma temporalizado.

\section{História de vida familiar e genograma}

Os estudos usando métodos de pesquisa qualitativa com famílias têm sido utilizados pelos pesquisadores das Ciências Sociais (BERTAUX, 1994; BERTAUX; BERTAUX-WIAME，2006; BERTAUX; DELCROIX, 2000; CUÉLLAR; 2004; GONZÁLEZ, 1995; PLUMMER, 2007). Suas abordagens envolvem, principalmente, aspectos geracionais relacionados à mobilidade social, religião, gênero e educação, entre outros. Em relação ao campo da Educação Ambiental, destacamos o estudo realizado por Garcia (2007) sobre transmissão geracional e processos de resiliência em famílias de pescadores de Rio Grande, Rio Grande do Sul, Brasil.

No caso do estudo que estamos relatando, os grupos familiares tiveram um papel central, pois constituíram a unidade de observação e análise para se interpretarem os significados da paisagem e a relação com os lugares. Essa escolha se justificou pelo seu caratér socializador, concretizado através dos processos educativos inerentes às relações no grupo familiar.

Na perspectiva de Bruschini (1989, p. 13), a família caracteriza-se por ser "uma unidade de relações sociais, no interior da qual os hábitos, valores e padrões de comportamento são transmitidos aos seus novos membros configurando-se assim, unidades de reprodução ideológica”. Para Bertaux e Thompson (1993), como grupo social, a família se configura como principal canal de transmissão de linguas, religião, valores sociais e aspirações, medos, visões de mundo, caminhos de comportamento, modelos de parentesco etc.

Segundo Szymanski (2000, p. 16), o caráter educativo da família "se justifica na finalidade de transmissão de saberes, hábitos e conhecimentos, em procedimentos que garantam a sua aquisição e fixação e na constante avaliação dos membros receptores quanto ao seu grau de assimilação do que lhes foi transmitido". Expresso de outro modo, a família é um espaço de interlocução e trocas subjetivas que ao longo de tempo se complexifica, oferecendo oportunidade de desenvolvimento para todos os envolvidos, sejam adultos, sejam crianças. 
A utilização da história de vida familiar tem sido considerada como uma possibilidade do método biográfico, se mostrando como uma extensão natural das histórias de vida (BERTAUX; DELCROIX, 2000; GONZÁLEZ, 1995). Segundo Marre (1991, p. 89), "muito mais que uma, entre outras, técnica de acesso a informações ou dados, a história de vida é parte essencial de um método biográfico cujo objetivo é - a partir da totalidade sintética que é o discurso específico de um indivíduo - reconstruir uma experiência humana vivida em grupo e de tendência universal". Constitui-se como "um locus privilegiado do encontro entre a vida intima do indivíduo e sua inscrição numa história social e cultural" (CARVALHO, 2003, p. 284).

Na visão de Bertaux (1994), as histórias de vida e histórias de família são ricas fontes de informação de feitos e de significados transmitidos através do específico prisma moral de seus grupos. O que se busca é que se tornem visíveis alguns dos processos-chave que contribuem para formar a sua história, não sendo esses processos necessariamente sociológicos, podendo ser (e muito frequentemente são) psicológicos. Nesse sentido, Rosemblat e Fischer (1993, p. 172) afirmam que os métodos qualitativos em estudos de familias são os "mais usados quando alguém quer perguntar sobre questões teóricas que envolvam significados, compreensões, percepções e outras subjetividades dentro das familias".

As histórias de família trazem materiais que não se preocupam somente com a vida da família e, por conseguinte, não somente com a sociologia da família, preocupam-se também, por exemplo, com o modo como as relações de gênero têm mudado historicamente; como a infância varia em um mesmo tempo histórico, de uma geração para outra; como migrantes se relacionam com um novo lugar (BERTAUX; DELCROIX, 2000).

Seguindo essa linha, concordamos com a perspectiva de González (1995, p. 135, tradução nossa), na qual a história de família é, "antes de tudo, narrações que nos documentam a não linearidade dos cursos de vida". Nessa visão, cada família ou indivíduo não é só um átomo mais afastado da sociedade, mas componente de um tecido social complexo de macroestruturas, ou seja, um fragmento que reproduz a totalidade. Em relação a isso, Bertaux e Delcroix (2000) destacam que uma das propriedades da história de família é sua função como um pequeno espelho da cultura geral, dos padrões sociais de mudança, da dinâmica societal e das ideias, na busca de entender esses padrões e suas dinâmicas de reprodução e transformação histórica.

$\mathrm{Na}$ visão de Cuéllar (2004), trabalhar com histórias de família significa localizar as eventualidades e buscar suas conexões nos sujeitos, ações e tempos. É nelas que se descrevem trajetórias individuais e grupais que constituem o núcleo sociológico de todo estudo de caso. Assim, a história de família é aberta e flexível e se potencializa quando os eventos narrados têm uma dimensão temporal contínua que relaciona o tempo individual, o familiar e o histórico.

Não seria adequado deixar de destacar que uma técnica importante e complementar ao estudo de famílias é o genograma, pois este propicia uma visão geral da estrutura familiar e de acontecimentos da família em um determinado tempo sócio-histórico. Conforme González (1995, p. 147), seu objetivo é 
precisamente uma visão esquemática, mais holística, das relações de parentes e "processos das trajetórias que queremos observar no tempo biográfico (as vidas) no tempo histórico".

Assim, dados como anos de nascimento e a trajetória conjugal (casamentos e separações), educativa, ocupacional e espacial, entre outros, são importantes para a organização e leitura das histórias de vida familiar. Todas essas informações registradas e organizadas graficamente nos permitem observar de forma global o conjunto de relações e propriedades de nosso objeto de estudo.

No caso desta pesquisa, procuramos descrever e analisar um conjunto de trajetórias individuais inseridas em um coletivo (família) em diferentes tempos e espaços sociais a fim de interpretar significados. Pretendemos ainda, através da história familiar (geracional), ir além do mero registro dos itinerários de vida e explorar os "significados que os membros de uma família dão em retrospectiva a suas próprias histórias de vida e às de seus parentes” (BERTAUX, 1994, p. 345346, tradução nossa).

A combinação entre o uso do genograma e das histórias de vida familiar (Figura 1) foi fundamental para o sucesso da organização e leitura dos dados, nos proporcionando outros níveis de interpretação a partir do entrecruzamento de sentidos comuns (ou não), sempre numa postura bermenêutica.

Figura 1. Esquema metodológico adotado na investigação. Após a realização das entrevistas (individuais e coletivas), procurou-se organizar as trajetórias individuais no contexto familiar concomitantemente ao genograma como etapa anterior à construção da história de vida familiar.

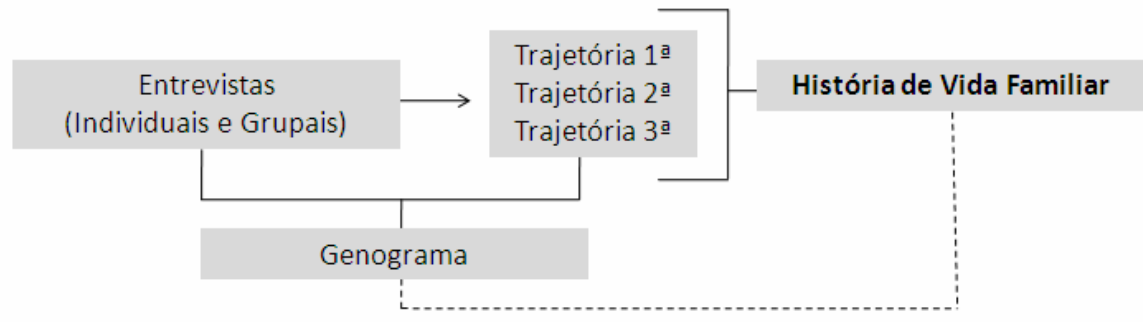

Na visão de Bertaux (1994), é claramente perceptível que, quando se trabalha com gerações ou histórias de famílias, as interações são sociologicamente muito significativas, destacando-se, cada vez mais, a necessidade de desenvolver métodos adequados para esse fim, isto é, que permitam compreender as interações de histórias individuais.

\section{O processo de análise e interpretação dos dados}

A coleta de dados constitui apenas a fase inicial do trabalho empírico. A concretização de uma pesquisa - produção de conhecimento científico - decorre da organização e tratamento desses dados, que é a etapa mais atrativa e desafiadora no processo de investigação. Quando falamos de análise e 
interpretação de informações geradas no campo da pesquisa qualitativa, estamos falando de um momento em que o pesquisador procura finalizar o seu trabalho, ancorando-se em todo o material coletado e articulando esse material aos propósitos da pesquisa e à sua fundamentação teórica (MINAYO, 1993).

O tratamento da informação qualitativa é um processo muito mais ambíguo, moroso, reflexivo, que se concretiza numa lógica de crescimento e aperfeiçoamento. A formatação do dispositivo não é previa ao tratamento de dados. Pelo contrário, constrói-se e consolida-se à medida que os dados vão sendo organizados e trabalhados no processo analítico e interpretativo (AFONSO, 2005). Essa etapa se caracteriza pela leitura repetida dos textos, o que faz com que o pesquisador se familiarize com a informação recolhida e possa dominar e organizar todo o material empírico a fim de consolidar a construção de um corpus. Nesse momento, tem-se por objetivo reduzir os dados a fim de interpretá-los (MILES; HUBERMAN, 1994; WOLCOTT, 1994), o que se caracteriza como um verdadeiro ato heurístico.

Em essência, o que se realiza é um processo de codificação dos dados, organizando-os em categorias e subcategorias (a priori e/ou emergentes) que apresentam núcleos de sentido que obdecem a critérios preestabelecidos. Essas categorias, segundo Gómez, Flores e Jiménez (1996), podem ser muito diversas, tais como espaciais, temporais e temáticas, sendo estas últimas as mais amplas e valiosas na análise de dados qualitativos.

Em relação a isso, Afonso (2005, p. 121) destaca que "o desenvolvimento de categorias de significação resulta da interação entre os eixos de análise que presidiram à concepção e operacionalização do dispositivo de coleta de dados, e as regularidades, padrões e tópicos, que emergem de leitura analítica dos textos". O investigador vai, assim, construindo uma lista (ou grelha) de categorias internamente consistentes, mas distintas umas das outras.

Quando os dados são organizados e apresentados num registro intepretativo, os esforços centram-se na construção do significado (AFONSO, 2005; WOLCOTT, 1994), isto é, centram-se na produção de um texto argumentativo que atribui novos sentidos aos fatos, situações e discursos dos atores, numa lógica compreensiva global. Como afirmam Jovchelovitch e Bauer (2004, p. 108), compreender uma história "é captar não apenas como o desenrolar dos acontecimentos é descrito, mas também a rede de relações e sentidos que dá à narrativa sua estrutura como um todo".

Nesta investigação, a utilização do programa computacional de análise de dados qualitativos $\mathrm{NVivo}^{8}$, da empresa QSR International, foi fundamental para a organização e categorização do material empírico. Segundo Tavares dos Santos (2001), o NVivo produz um ambiente informacional no qual se podem criar, gerenciar e explorar ideias e categorias, minimizando-se as rotinas de trabalho e

\footnotetext{
${ }^{8}$ O programa QSR NVivo faz parte da emergência do CAQDAS - Computer Assisted Qualitative Data Analysis Software -, que, segundo Tavares dos Santos (2001), configurou um campo intelectual na investigação social cujas possibilidades apenas se vislumbram.
} 
maximizando-se a flexibilidade da análise, para descobrir novas ideias e desenvolvêlas. Além disso, representou economia de tempo e potencializou a análise dos dados.

\section{(Re)Construindo as histórias de vida familiar}

A reconstrução da história de vida familiar constituiu a primeira etapa de organização do material empírico. Assim, em nossa experiência, após as transcrições das entrevistas em profundidade e de leituras sucessivas, procurouse descrever o percurso familiar identificando-se os contextos sócio-históricos, atores, situações e falas carregadas de significados que pudessem, antes de qualquer coisa, descrever as experiências vividas no grupo familiar até a chegada no lugar de destino.

Essa etapa inicial permitiu construir o perfil familiar e aprofundar as categorias estabelecidas a prior ${ }^{9}$, bem como estabelecer novas categorias e subcategorias que tratassasem de temporalizar e tematizar a trajetória familiar (Tabela 1).

Tabela 1. Categorias utilizadas na composição das histórias.

\begin{tabular}{|c|c|}
\hline Categoria I & Lugar de Origem \\
\hline Subcategoria A & A comunidade: os Grupos de Convívio \\
\hline Subcategoria B & O Ambiente e as Questões Socioambientais \\
\hline Categoria II & Migração \\
\hline Subcategoria n & Emergentes \\
\hline Categoria III & Lugar de Destino \\
\hline Subcategoria A & O Assentamento: Os Grupos de Convívio \\
\hline Subcategoria B & O Ambiente e as Questões Socioambientais \\
\hline
\end{tabular}

Concluída essa etapa, em primeiro lugar tratamos de organizar os excertos de acordo com as categorias (a priori e emergentes), priorizando as narrativas das gerações em ordem crescente. Em segundo lugar, agrupamos unidades de texto que permitissem descrever e interpretar os contextos de vida dos participantes, estabelecendo conexões entre as partes de modo a constituir um relato único. Em terceiro e último lugar, complementamos o material com informações sóciohistóricas, imagens (fotos e mapas) e alguns comentários e interpretações sociológicas.

\footnotetext{
${ }^{9}$ Nesta pesquisa, as categorias estabelecidas a priori para a construção da história de vida familiar foram embasadas em estudos sobre apego ao lugar por comunidades migrantes: Brehm (2007), Brehm, Eisenhauer e Krannich (2004) e Burholt e Naylor (2005).
} 
Esse percurso, marcadamente técnico, exigiu retomar a história a partir dos referenciais bibliográficos sobre o grupo social e cruzá-la com as próprias histórias narradas, seguindo uma postura interpretativa.

\section{Interpretando os significados da paisagem e a relação com o lugar}

A busca por revelar os significados da paisagem e a relação com os lugares (de origem e de destino) a partir das narrativas individuais e ancoradas na história da família constituiu a segunda etapa de análise dos dados. Essa tarefa se tornou um grande desafio, pela complexidade da análise dos contextos que envolvem os percursos individuais e coletivos e pela complexidade do campo teórico que envolve os estudos sobre paisagem e lugar.

Da mesma forma que na primeira etapa de análise - história de vida familiar -, foram necessárias leituras sistemáticas em profundidade das narrativas individuais com um intenso cruzamento com o campo teórico. Procurou-se, além de descrever os significados, interpretá-los nos contextos em que surgiam a fim de destacar as dimensões psicológicas e os contextos sócio-históricos da trajetória vital dos indivíduos.

Para a análise dos significados da paisagem e a relação com os lugares não se estabeleceram categorias a priori; estas foram sendo construídas de forma indutiva. Primeiramente, estabeleceram-se categorias emergentes gerais (Paisagem privilegiando o ambiente natural, Paisagem privilegiando a vida social e Paisagem privilegiando o contexto socioambiental) e a análise foi realizada sem levar em consideração as diferentes gerações. Posteriormente, procurou-se interpretar os dados de forma comparativa entre as gerações, com o objetivo de evidenciar nuances de significados relativizadas a partir da trajetória individual e familiar, dentro de cada categoria previamente delimitada.

\section{Considerações finais}

Neste trabalho, procurou-se descrever e problematizar o percurso da construção de um método capaz de interpretar os significados da paisagem e a relação de migrantes com os lugares (de origem e de destino) com base nas histórias de vida familiar. Considerou-se que as trajetórias individuais do grupo social estudado tomam lugar, em especial, no contexto das relações que se estabelecem na família e na comunidade, sendo esses espaços sociais determinantes na constituição dos sujeitos e seus significados.

O método exigiu constantes desafios e adaptações, configurando-se como um momento de aprendizagem aos pesquisadores. Nesse processo, elementos como a elaboração de critérios que dessem conta de selecionar a amostra com as respectivas gerações, a identificação e aproximação com as famílias numa postura flexível e participativa, a organização dos dados (entrevistas individuais e coletivas) para a composição das trajetórias familiares e o desenvolvimento da capacidade de articulação de múltiplas narrativas sobre um determinado tema fizeram parte de um caminho de aprendizagens coletivas. Enquanto método 
biográfico, destaca-se a sua potencialidade para a leitura das trajetórias de grupos sociais em que a família é um grupo de convívio característico.

A estratégia de pesquisa centrada nas narrativas de indivíduos pertencentes a diferentes gerações de uma mesma família gerou múltiplas perspectivas para compreender as relações sociais dentro do grupo familiar e social. Cada entrevista representou uma única leitura de uma experiência comum familiar; tomadas juntas, permitiram a construção de uma visão holística da história da familia.

Interpretar os significados da paisagem e a relação com o lugar, tendo como base as narrativas dos sujeitos sobre as histórias de vida famíliar, contribuiu para uma análise longitudinal e dos contextos em que determinada narrativa sobre o objeto de estudo se apresentava, proporcionando outros níveis de interpretação além do social. Além disso, a abordagem biográfica geracional permitiu evidenciar os processos de socialização dentro do grupo familiar e social em relação aos significados da paisagem e a relação com o lugar.

Além de reconhecermos a necessidade de desenvolvimento do método História de Vida Familiar - no campo da pesquisa em Educação Ambiental, destacamos sua particularidade por permitir outros níveis de interpretação da relação dos sujeitos e grupos sociais com a paisagem e os lugares. Essas leituras são fundamentais ao desenvolvimento de estratégias de intervenção no campo educativo-ambiental, no qual as famílias são o foco de investigação.

\section{Referências}

AFONSO, Natércio. Investigação Naturalista em Educaşão: um guia prático e crítico. Porto: ASA, 2004. 223 p. (Coleção Em Foco).

ALONSO, Luis Enrique. Sujeto y Discurso: El lugar de la entrevista abierta en las prácticas de la sociología cualitativa. In: DELGADO, Juan Manuel; GUTIÉRREZ, Juan (Org.). Métodos y Técnicas Cualitativas de Investigación en Ciencias Sociales. Madrid: Sínteses, 1995. p. 225-240.

BERTAUX, Daniel. Los relatos de vida en el análisis social. Historia y Fuente Oral, Barcelona, n. 1, p. 87-96, 1989.

Genealogías sociales comentadas y comparadas. Una propuesta metodológica. Traducción de Jorge A. González. Estudios sobre las Culturas Contemporáneas, Colima, México, v. 6, n. 16-17, p. 333-349, 1994.

BERTAUX, Daniel; BERTAUX-WIAME, Isabelle. Heritage and its Lineage: A Case History of Transmission and Social Mobility over Five Generations. In: BERTAUX, Daniel; THOMPSON, Paul (Org.). Pathways to social class: a qualitative approach to social mobility. New Brunswick: Transaction, 2006. p. 62-97.

BERTAUX, Daniel; DELCROIX, Catherine. Case Histories of Families and Social Processes: Enriching Sociology. In: CHAMBERLAYNE, Prue; BORNAT, Joanna; 
WENGRAF, Tom (Ed.). The Turn to Biographical Methods in Social Science: Comparative Issues and Examples. London: Routledge, 2000. p. 71-89.

BERTAUX, Daniel; THOMPSON, Paul. Introduction. In: BERTAUX, Daniel; THOMPSON, Paul (Ed.). Between Generations: Family Models, Myths and Memories. Oxford: Oxford University Press, 1993. p. 1-12.

BOGDAN, Robert; TAYLOR, Steven. Introduction to qualitative research methods. New York: John Wiley \& Sons, 1975. 266 p.

BOURDIEU, Pierre. La distinción: criterios y bases sociales del gusto. Traducción de María del Carmen Ruiz de Elvira. Madrid: Taurus, 1987.

BOWEN, Glenn. Naturalistic inquiry and the saturation concept: a research note. Qualitative Research, v. 8, n. 1, p. 137-152, 2008.

BREHM, Joan M. Community Attachment: The Complexity and Consequence of the Natural Environment Facet. Human Ecology, v. 35, p. 477-488, 2007.

BREHM, Joan M.; EISENHAUER, Brian W.; KRANNICH, Richard S. Dimensions of community attachment and their relationship to well-being in the amenity-rich rural West. Rural Sociology, v. 69, n. 3, p. 405-429, 2004.

BRUSCHINI, Cristina. Uma abordagem sociológica da família. Revista Brasileira de Estudos de População, São Paulo, v. 6, n. 1, p. 1-23, 1989.

BURGESS, Robert G. A pesquisa de terreno: uma introdução. Tradução de Eduardo de Freitas e Maria Inês Mansinho. Oeiras, Portugal: Celta, 1997. 262 p.

BURHOLT, Vanessa; NAYLOR, Dawn. The relationship between rural community type and attachment to place for older people living in North Wales, UK. European Journal of Ageing, v. 2, n. 2, p. 109-119, 2005.

BUT'T, Richard; RAYMOND, Danielle; MCCUE, Glenda; YAMAGISHI, Lloyd. La autobiografía colaborativa y la voz del profesorado. In: GOODSON, Ivor F. (Ed.). Historias de vida del profesorado. Traducción de Aída Sánchez de Serdio. Barcelona: Octaedro - EUB, 2004. p. 99-148.

CALLEJAS, Germán Vargas. Diseño metodológico de una investigación cualitativa: un estudio de caso. In: CARTEA, Pablo Ángel Meira; TORALES, Marília Andrade (Org.). Investigación e Formación en Educación Ambiental - novos escenarios e enfoques para un tempo de cambios. Coruña: Centro de Extensión Universitaria e Divulgación Ambiental de Galicia, 2008. p. 99-126.

CARVALHO, Isabel Cristina de Moura. A Invenção Ecológica. Narrativas e Trajetórias da Educação Ambiental no Brasil. 2. ed. Porto Alegre: UFRGS, 2002. 229 p.

Biografia, identidade e narrativa: elementos para uma análise hermenêutica. Horizontes Antropológicos, Porto Alegre, ano 9, n. 19, p. 283-302, 2003.

CHASE, Susan E. Narrative Inquiry: Multiple Lenses, Approaches, Voices. In: DENZIN, Norman K.; LINCOLN, Yvonna S. (Ed.). Handbook of Qualitative Research. 2nd ed. Thousand Oaks, CA: SAGE, 2000. p. 651-679. 
CUÉLLAR, Karla Covarrubias. La historia de familia: una propuesta metodologica para el estudio de la pobreza en familias evangélicas de Colima, México. Estudios sobre las culturas contemporáneas, Colima, México, v. 10, n. 20, p. 225-240, 2004.

DEMO, Pedro. Metodologia Científica em Ciências Sociais. São Paulo: Atlas, 1981. 255 p.

GARCIA, Narjara Mendes. Educação nas famílias de pescadores artesanais: transmissão geracional e processos de resiliência. 2007. 87 f. Dissertação (Mestrado em Educação Ambiental) - Programa de Pós-Graduação em Educação Ambiental, Fundação Universidade Federal do Rio Grande, Rio Grande, 2007.

GASKELL, George. Entrevistas individuais e grupais. In: BAUER, Martin; GASKELL, George (Org.). Pesquisa qualitativa com imagem, texto e som: um manual prático. Tradução de Pedrinho Guareschi. Petrópolis: Vozes, 2004. p. 64-89.

GHIGLIONE, Rodolphe; MATALON, Benjamin. O inquérito: teoria e prática. Tradução de Conceição Lemos Pires. Oeiras, Portugal: Celta, 2005. 336 p.

GÓMEZ, Gregorio Rodríguez; FLORES, Javier Gil; JIMÉNEZ, Eduardo García. Metodología de la investigación cualitativa. Archidona, Málaga: Aljibe, 1996. 378 p.

GONZÁLEZ, Jorge A. Y todo queda entre familia. Objeto y método para historias de familias. Estudios sobre las Culturas Contemporáneas, Colima, México, v. 1, n. 1, p. 135-154, jun. 1995.

GOODSON, Ivor F. (Ed.). Historias de vida del profesorado. Traducción de Aída Sánchez de Serdio. Barcelona: Octaedro - EUB, 2004.

JOVCHELOVITCH, Sandra; BAUER, Martin W. Entrevista narrativa. In: BAUER, Martin W.; GASKELL, George (Org.). Pesquisa qualitativa com texto, imagem e som: um manual prático. Tradução de Pedrinho Guareschi. Petrópolis: Vozes, 2002. p. 90-113.

LISBOA, Cassiano Pamplona. (Re)contando Histórias: o ambiente tematizado a partir dos itinerários de vida. 2007. 180 f. Dissertação (Mestrado em Educação) - Faculdade de Educação, Universidade Federal do Rio Grande do Sul, Porto Alegre, 2007.

MARRE, Jacques Leon. História de vida e método biográfico. Cadernos de Sociologia, Porto Alegre, v. 3, n. 3, p. 89-141, 1991.

MIDDLETON, Sue. El desarrollo de una pedagogía radical: autobiografía de una socióloga neozelandesa sobre la educación de las mujeres. In: GOODSON, Ivor F. (Ed.). Historias de vida del profesorado. Traducción de Aída Sánchez de Serdio. Barcelona: Octaedro - EUB, 2004. p. 63-97.

MILES, Matthew B.; HUBERMAN, A. Michael. An Expanded Sourcebook: Qualitative Data Analysis. $2^{\text {nd }}$ ed. Thousand Oaks, CA: SAGE, 1994. 338 p.

MINAYO, Maria Cecília de Souza. O desafio da pesquisa social. In: (Org.). Pesquisa Social: Teoria, método e criatividade. Petrópolis: Vozes, 1993. p. 9-29.

MORAES, Roque. Mergulhos Discursivos: análise textual qualitativa entendida como processo integrado de aprender, comunicar e interferir em discursos. In: GALIAZZI, Maria do Carmo; FREITAS, José Vicente de (Org.). Metodologias Emergentes de Pesquisa em Educação Ambiental. 2. ed. Ijuí, RS: Unijuí, 2007. p. 85-114. 
NVIVO qualitative data analysis software. Version 2. [S.I.]: QSR International Pty Ltd., 2002.

PÉREZ SERRANO, Gloria. Investigación Cualitativa. Retos e Interrogantes. Métodos, Técnicas y Análisis de Datos. Madrid: La Muralla, 1994. (2 v.).

PLUMMER, Ken. Documents of life 2: an invitation to a critical humanism. London: SAGE, 2007. 306 p.

QUIVY, Raymond; CAMPENHOUDT, Luc Van. Manual de investigação em ciências sociais. Tradução de João Minhoto Marques e Maria Amália Mendes. Lisboa: Gradiva, 1995. 282 p.

ROSEMBLAT, Paul C.; FISCHER, Lucy Rose. Qualitative Family Research. In: BOSS, Pauline; DOHERTY, William J.; LAROSSA, Ralph; SCHUMM, Walter R.; STEINMETZ, Suzanne K. (Ed.). Sourcebook of Family Theories and Methods: A Contextual Approach. New York: Springer, 1993. p. 167-181.

SZYMANSKI, Heloisa. A família como um locus educacional: perspectivas para um trabalho psicoeducacional. Rev. Bras. Est. Pedag., v. 81, n.197, p. 14-25, 2000.

TAVARES DOS SANTOS, José Vicente. As possibilidades das metodologias informacionais nas práticas sociológicas: por um novo padrão de trabalho para os sociólogos do século XXI. Sociologias, Porto Alegre, ano 3, n. 5, p. 116-148, jan./jun. 2001 .

TORALES, Marília Andrade. A práxis da educação ambiental como processo de decisão pedagógica: um estudo biográfico com professoras de Educação Infantil na Galiza (Espanha) e no Rio Grande do Sul (Brasil). 2006. 566 f. Tese (Doutorado em Ciências da Educação) Faculdade de Ciências da Educação, Universidade de Santiago de Compostela, Santiago de Compostela, 2006.

- Pesquisa qualitativa: o estudo biográfico como opção metodológica para compreender a práxis da Educação Ambiental. In: CARTEA, Pablo Ángel Meira; TORALES, Marília Andrade (Org.). Investigación e Formación en Educación Ambiental: Novos escenarios e enfoques para un tempo de cambios. Coruña: Centro de Extensión Universitaria e Divulgación Ambiental de Galicia, 2008. p. 77-97.

WOLCOTT, Harry F. Transforming Qualitative Data: description, analysis, and interpretation. Thousand Oaks, CA: SAGE, 1994. 433 p.

Artigo recebido em 9/8/2011 e aprovado em 16/12/2011. 